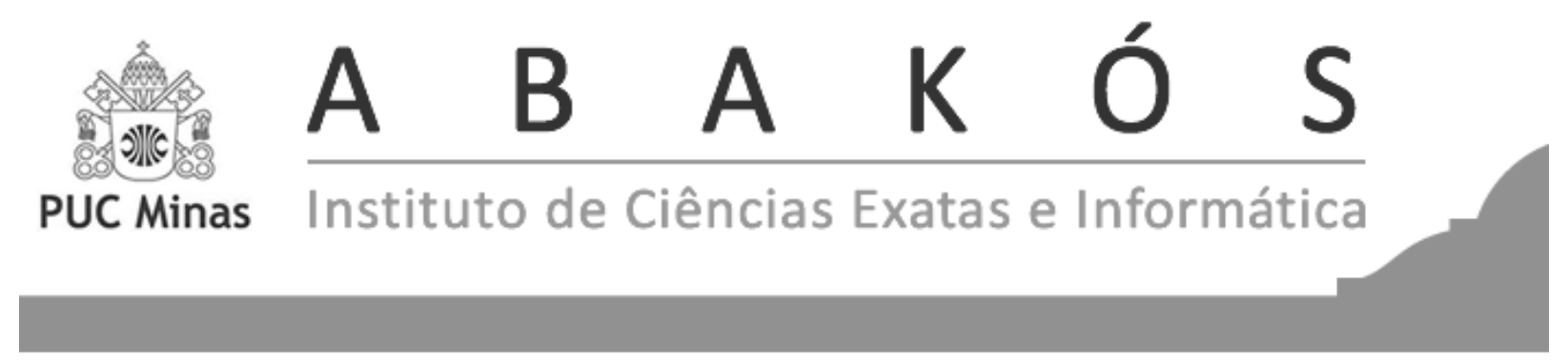

cc) (†)

\title{
Eratóstenes nos Dias de Hoje e a Crença na Terra Plana*
}

Eratosthenes Today and the Belief in the Flat Earth

\author{
Igor Passos dos Santos ${ }^{1}$ \\ João Damazio Vale Carvalho Filho ${ }^{2}$ \\ Ricardo Roberto Plaza Teixeira ${ }^{3}$
}

\begin{abstract}
Resumo
Este artigo analisa a implementação do experimento de Eratóstenes no Brasil dos dias de hoje. A partir de questionamentos trazidos pelos próprios estudantes, foi incorporada a ideia de usar ferramentas tecnológicas de comunicação para a realização de medições do tamanho das sombras de hastes verticais de um metro de altura, geradas pelos raios solares, simultaneamente, nas cidades de Pedreiras - MA e São Paulo - SP, de modo análogo à ideia do experimento proposto por Eratóstenes, na antiguidade, para determinar o tamanho de nosso planeta. Além disso, este trabalho busca refletir sobre as relações do terraplanismo, como movimento de negação da ciência, com o conceito de pós-verdade e sobre a natureza e os métodos utilizados em observações experimentais com características científicas.
\end{abstract}

Palavras-chave: História da Ciência. Ensino de Física. Negação da Ciência. Observação experimental. Astronomia.

\footnotetext{
* Submetido em 27/09/2020 - Aceito em 23/08/2021

${ }^{1}$ Licenciado em Física pelo campus de São Paulo do Instituto Federal de São Paulo (IFSP) e docente na Escola Santa Marina, São Paulo (SP), Brasil-passos.igor88@gmail.com

${ }^{2}$ Licenciado em Matemática pelo campus de Pedreiras da Universidade Estadual do Maranhão (UEMA), Brasiljoaofilhoxavier2016@gmail.com

${ }^{3}$ Doutor em Física pela USP e docente do campus de Caraguatatuba do Instituto Federal de São Paulo (IFSP), Brasil-rteixeira@ifsp.edu.br
} 


\begin{abstract}
We analyze the implementation of Eratosthenes' experiment between two Brazilian cities. Considering questions brought by the students, we incorporated the idea of using technological communication tools to measure simultaneously the size of the shadows of vertical rods of one meter high, generated by the sun's rays, in the cities of Pedreiras - MA and São Paulo - SP, similarly to the idea of the experiment proposed by Eratosthenes, in antiquity, to determine the size of our planet. In addition, this work seeks to reflect on the relations of the flat Earth belief, as a movement of denial of science, with the concept of post-truth and on the nature and methods used in experimental observations with scientific characteristics.
\end{abstract} Keywords: History of Science. Physics teaching. Science denial. Experimental observation. Astronomy. 


\section{INTRODUÇÃO}

A ideologia do terraplanismo (movimento que defende que a Terra tem o formato de um disco plano, ou seja, que ela não tem um formato aproximado de uma esfera) é com certeza o exemplo mais famoso de negação da ciência existente na atualidade (OLSHANSKY et al., 2018). Na segunda metade da década de 2010, este movimento adquiriu força no mundo todo e, em particular, no Brasil. Um fator decisivo para que isto ocorresse foi o uso das redes sociais e, sobretudo, do site YouTube de armazenamento de vídeos como ferramentas para a disseminação dessa crença. Em um trabalho realizado junto a adeptos da ideia de que a Terra é plana, a esmagadora maioria afirmou que foram convencidas disso após assistirem vídeos no YouTube; além disso, uma grande parte delas acessou esses vídeos a partir de sugestões feitas pelo algoritmo da própria plataforma, sendo que muitas dessas recomendações aconteceram após elas assistirem vídeos envolvendo teorias da conspiração sobre os atentados de 11 de setembro de 2001 ou sobre a viagem do homem à Lua (LANDRUM, 2019).

No Brasil, uma pesquisa realizada em 2019 pelo Instituto Datafolha indicou que cerca de $7 \%$ dos brasileiros acreditam que a Terra seja plana (GARCIA, 2019). Se percentualmente o número parece pequeno, em termos absolutos ele significa que mais de 10 milhões de brasileiros acreditam em uma ideia que vem sendo negada ao longo dos últimos dois mil anos por pesquisas, observações e experimentos os mais diversos possíveis.

As diferentes formas de negação da ciência se articulam entre si: parte significativa dos terraplanistas é também criacionista, negando a Teoria da Evolução de Charles Darwin e explicando a origem da Terra, dos seres vivos e do ser humano a partir do Antigo Testamento, a parte inicial da Bíblia cristã (ALVIM, 2017). O fenômeno do terraplanismo está também relacionado a uma valorização do ponto de vista pessoal e dos sentidos individuais em detrimento do consenso científico e dos saberes coletivamente organizados ao longo da História (PIVARO, 2019). A ideia de que a Terra seja plana não pode ser sequer considerada uma teoria, pois há inúmeros modelos diferentes de Terra plana, incluindo alguns que se contradizem entre si.

A pós-verdade - que pode ser definida como a situação na qual os fatos objetivos têm menos influência que os apelos às emoções e às crenças pessoais para a formação da opinião pública - tem um de seus pilares calcados na erosão da confiança nas instituições: nos governos, na mídia e, também, na ciência (D’ANCONA, 2018). Nesse cenário é importante refletir criticamente sobre o papel desempenhado pela educação científica na formação dos cidadãos. Aos alunos, durante a educação básica, é ensinado sobre o formato esférico da Terra, em disciplinas como Geografia, Ciências e Física; entretanto, há dados de pesquisas que revelam que são poucos os livros didáticos que trabalham com explicações mais aprofundadas sobre este tema (ROSA; DARROZ; TYBURSKI, 2018). Sendo assim, alguns cidadãos têm sido convencidos, de modo crescente, por argumentos de que a Terra seria plana, ao assistirem certos vídeos disponibilizados na internet. Isso indica que cientistas, professores, jornalistas e divulgadores da ciência em geral têm a importante incumbência de encontrar estratégias para superar esta situação. 


\section{A MEDIÇÃO DA CIRCUNFERÊNCIA DA TERRA POR ERATÓSTENES}

O primeiro ser humano a observar com os próprios olhos a esfericidade da Terra foi o astronauta russo Yuri Gagarin em 1961 (BEZERRA, 2019), entretanto, há mais de dois mil anos antes, o grego Eratóstenes (276 a.C.-194 a.C.) usando os conhecimentos disponíveis na época, a observação de sombras, o raciocínio lógico e um pouco de inventividade concluiu (sem viajar para o espaço) que a Terra teria o formato esférico, ou seja, que a Terra não seria um disco plano. O historiador da ciência Crease (2006) considera este um dos 10 mais belos experimentos científicos da história, pela sua engenhosidade e pelas ferramentas simples que usa.

Um dos pressupostos básicos da proposta de Eratóstenes é que o Sol está situado a uma distância extremamente grande da Terra, de modo que os raios solares que incidem sobre a superfície terrestre são praticamente paralelos (SANTOS; VOELZKE; ARAÚJO, 2012), o que é muito razoável pelos dados e informações que temos hoje. Em um trecho do primeiro episódio (intitulado "The Shores of the Cosmic Ocean" ou, em português, "Os limites do Oceano Cósmico") da série de documentários científicos "Cosmos", produzida pelo físico Carl Sagan (1934-1996) e lançada em 1980, há uma explicação bastante didática do procedimento adotado por Eratóstenes para estabelecer a esfericidade da Terra e medir sua circunferência. $\mathrm{Na}$ plataforma de compartilhamento de vídeos YouTube, esse trecho (dublado em português) está disponibilizado na forma de um vídeo intitulado "Eratóstenes e a circunferência da Terra" 4 com duração de 6 minutos e 42 segundos. A mesma plataforma disponibiliza esse mesmo trecho, com a narração original de Carl Sagan em inglês e legendado em português, intitulado "Carl Sagan - Eratóstenes" 5 .

Eratóstenes viveu a maior parte da sua vida no século III a.C. Ele nasceu em 276 a.C. em Cirene, uma antiga colônia grega situada no nordeste da atual Líbia, próxima à fronteira com o Egito e perto da costa do Mar Mediterrâneo, na região que hoje é chamada de Cirenaica: as ruínas de Cirene estão atualmente localizadas na cidade líbia de Xaate, no distrito de Jabal Acdar. $\mathrm{Na}$ antiguidade, o equivalente ao "sobrenome" de uma pessoa era a sua cidade de nascença: esse é o motivo pelo qual ele é conhecido como Eratóstenes de Cirene. Sua morte ocorreu em 194 a.C. em Alexandria, cidade portuária situada no norte do Egito, junto à costa do Mar Mediterrâneo e perto da foz do Rio Nilo. Alexandria, fundada por Alexandre, o Grande (356 a.C.-323 a.C.), em 331 a.C., também é uma cidade tributária da cultura greco-romana, como muitas outras cidades da costa do Mediterrâneo no norte da África. Desde a sua fundação até aproximadamente o final da Antiguidade, por cerca de oito séculos, Alexandria sediou a maior biblioteca de sua época que acabou por se tornar um grande centro educacional e de difusão da cultura grega, uma espécie de "universidade" daquele período histórico. Hoje Alexandria é a segunda maior cidade egípcia, com mais de 5 milhões de habitantes; em 2002, foi inaugurada em Alexandria a maior biblioteca do Egito, em um grande e belo prédio (Figura 1), com o

\footnotetext{
${ }^{4}$ Disponível em: <https://www.youtube.com/watch?v=fu9Z7YuXLVE>. Acesso em: 26 set. 2020.
}

${ }^{5}$ Disponível em: <https://www.youtube.com/watch?v=mnfrgF5FEkY>. Acesso em: 26 set. 2020. 
objetivo de tentar rememorar e homenagear a importância da antiga biblioteca de Alexandria.

\section{Figura 1 - Nova Biblioteca de Alexandria, inaugurada em 2002}

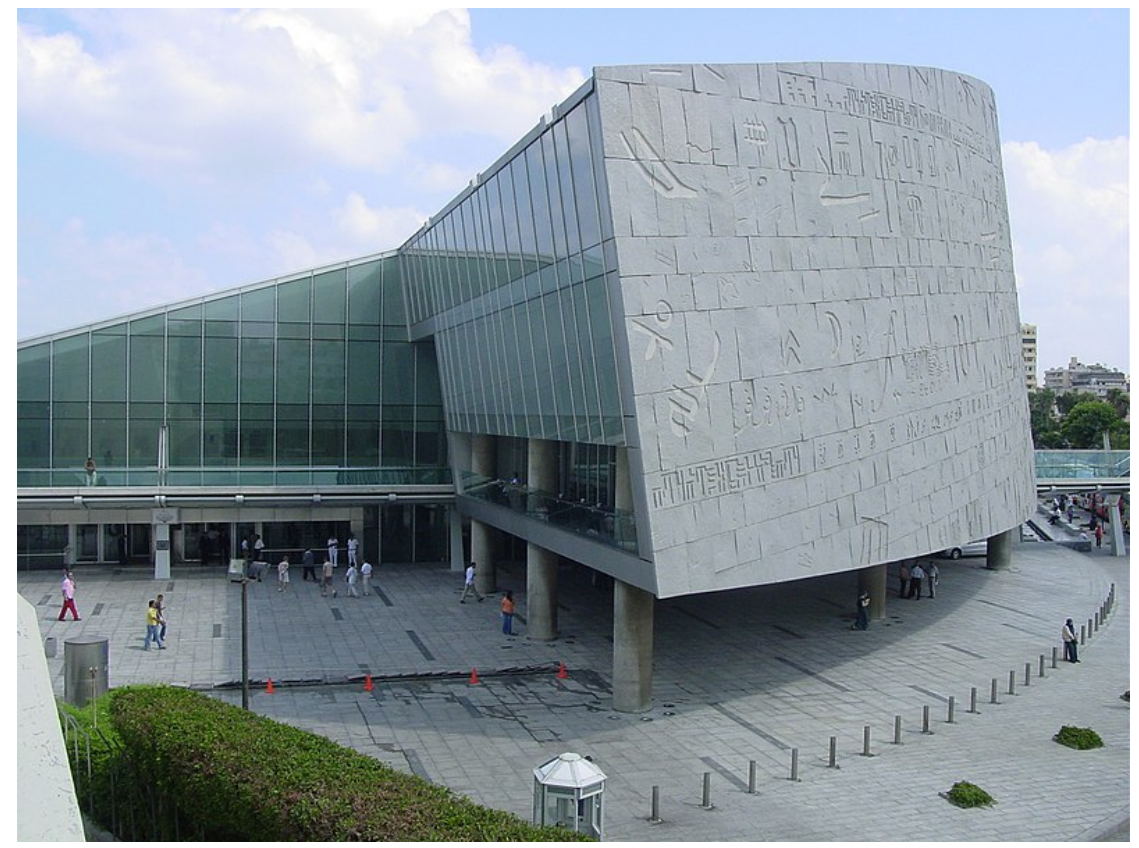

Fonte: <https://commons.wikimedia.org/wiki/File:Bibliotheca_Alexandrina_plaza_003.jpg >.

Para a sua formação como geômetra (matemático) e astrônomo, Eratóstenes estudou em Cirene, Atenas e Alexandria, três importantes centros de produção intelectual da cultura helenística da antiguidade. O "mundo conhecido" na época pelos gregos era composto pelo sul da Europa, pelo norte da África e pelo Oriente Médio. As três cidades citadas anteriormente e que foram importantes para a formação de Eratóstenes estavam situadas junto ao Mar Mediterrâneo que em certo sentido banhava o centro do mundo helenístico e permitia, por meio da navegação, o transporte entre essas cidades. A maior contribuição de Eratóstenes está no fato de ele ter evidenciado a esfericidade da Terra e, inclusive, estimado o tamanho da circunferência da esfera terrestre, usando, para isso, apenas de conhecimentos de geometria, de informações sobre distâncias entre duas cidades situadas no norte da África (Alexandria e Siena) e das medidas dos tamanhos de sombras de hastes verticais situadas nessas cidades em um dia e horário específicos.

"O Egito é uma dádiva do Rio Nilo": esse truísmo procura explicar que é graças às águas do Rio Nilo - com a capacidade de fertilizar as terras situadas nas suas margens - que se estruturou há cerca de 5 milênios uma das mais antigas civilizações da história da Humanidade. $\mathrm{O}$ rio Nilo corre de forma bem aproximada no sentido do sul para o norte, atravessando o grande deserto do Saara situado em toda a região norte do continente africano. Nesse território situado no nordeste da África, aproximadamente entre os séculos XXX a.C. e IV a.C., as várias dinastias de faraós se sucederam para governar o Egito da antiguidade. O Egito árabe de hoje é algo bem diferente, pois é estruturado a partir da cultura islâmica que se disseminou pelo oriente médio e norte da África, a partir do século VII d.C. Entre os dois períodos, ou seja, entre os séculos IV a.C. e VII d.C. muitas colônias gregas (e depois romanas) foram estabelecidas no Egito, configurando u m período de forte influência he lenística (g rega). Foi ne sse período do 
Egito helenístico que viveu Eratóstenes.

Bem ao sul do Egito, também nas margens do Rio Nilo, está atualmente a cidade de Assuã (em inglês, Aswan) que na antiguidade era conhecida por Siena (não confundir com a cidade com o mesmo nome Siena e que está situada na Itália). Essa cidade (Figura 2) hoje está situada nas proximidades da grande represa de Assuã, com o maior lago artificial do Egito, que foi construído nos anos 1960 para represar o Rio Nilo e gerar energia elétrica para o país, de modo a contribuir com o seu desenvolvimento econômico. A região ao sul de Assuã, compartilhada pelas atuais nações do Egito e do Sudão, constituía a chamada Núbia. Caminhando pelas margens ou navegando pelo rio Nilo, já se sabia na época que a distância entre Siena/Assuã e Alexandria (situada próxima ao delta do Nilo) é de pouco mais que $1000 \mathrm{~km}$, obviamente nas unidades usadas naquela época (estádios). Em linha reta, a distância entre as duas cidades é obviamente menor, de cerca de $850 \mathrm{~km}$. As duas cidades não estão localizadas exatamente na mesma longitude, portanto a linha ao longo da superfície do globo terrestre ligando Siena/Assuã até a cidade de Alexandria tem uma leve inclinação para noroeste.

\section{Figura 2 - Cidade atual de Assuã (antiga Siena), nas margens do Rio Nilo}

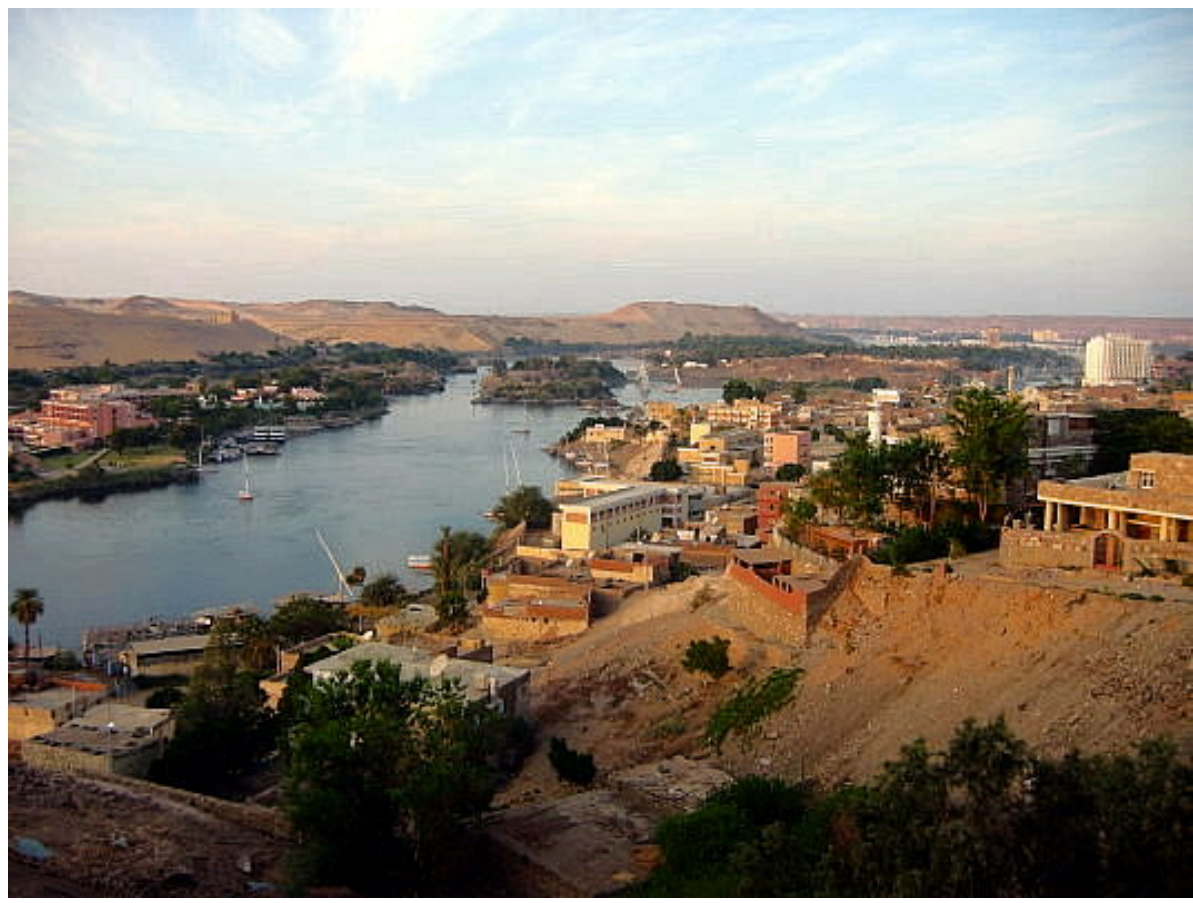

Fonte: <https://commons.wikimedia.org/wiki/File:City_of_Aswan_seen_from_the_air.jpg>.

Hoje sabemos que Siena/Assuã tem latitude $+24,09^{\circ}$ e longitude $+32,90^{\circ}$, enquanto Alexandria tem latitude $+31,22^{\circ}$ e longitude $+29,96^{\circ}$; esses dados foram obtidos pelo site $<$ latitude longitude.org $>$. Uma latitude positiva significa que a cidade está ao norte da linha do Equador, que define a latitude zero, enquanto uma longitude positiva significa que a cidade está a oeste do meridiano de Greenwich que passa sobre a cidade de Londres e define a longitude zero. Como trata-se de trigonometria esférica, usando uma calculadora online para determinar o ângulo central do arco de círculo máximo entre dois pontos da superfície da Terra (como a disponível no link <https://www.vcalc.com/wiki/MichaelBartmess/Great+Circle+Central+Angle $>$ ) e inserindo-se os valores das latitudes e longitudes das duas cidades, obtém-se que o ângulo 
central do arco de círculo máximo entre essas duas localidades é de aproximadamente $7,6^{\circ}$. O mesmo resultado pode ser obtido utilizando-se uma calculadora online para triângulos esféricos (como por exemplo as existentes nos links <http://www.movable-type.co.uk/scr ipts/latlong.html?from $=49.243824,-121.887340 \&$ to $=49.227648,-121.89631>,<$ https: //keisan.casio.com/exec/system/1224587128> e <https://www.nhc.noaa.gov/gccalc.shtml >), obtendo-se a distância, ao longo do círculo máximo entre as duas cidades a partir das suas latitudes e longitudes, e dividindo a distância obtida pelo raio da Terra (cerca de $6371 \mathrm{~km}$ ), para obter o ângulo central de 0,1325 rad ou aproximadamente $7,6^{\circ}$. Esse é um valor que está bem próximo de $1 / 50$ da circunferência completa, pois $360^{\circ} / 50=7,2^{\circ}$. Em números aproximados, assumindo uma distância aproximada de $800 \mathrm{~km}$ entre as duas cidades (Figura 3), é possível concluir que o comprimento da circunferência do globo terrestre é 50 vezes maior que a distância entre as duas cidades, ou seja, de cerca de $40.000 \mathrm{~km}=50 \times 800 \mathrm{~km}$.

A esse propósito, o fato de a circunferência da Terra ser uma quantidade próxima de um "número redondo" como 40 mil quilômetros, não é uma coincidência. Esse "número redondo" se deve à própria definição do metro que, após a Revolução Francesa, em 1793, foi estabelecido como sendo igual a um décimo de milionésimo da distância entre o Polo Norte e o Equador, passando pelo meridiano da França. Portanto a distância entre o Polo Norte e o Equador é igual a 10 milhões de metros ou 10 mil quilômetros e a circunferência da Terra, que vale o quádruplo disso, tem que ser de 40 mil quilômetros.

\section{Figura 3 - Distância em linha reta entre as cidades de Alexandria e Siena/Assuã}

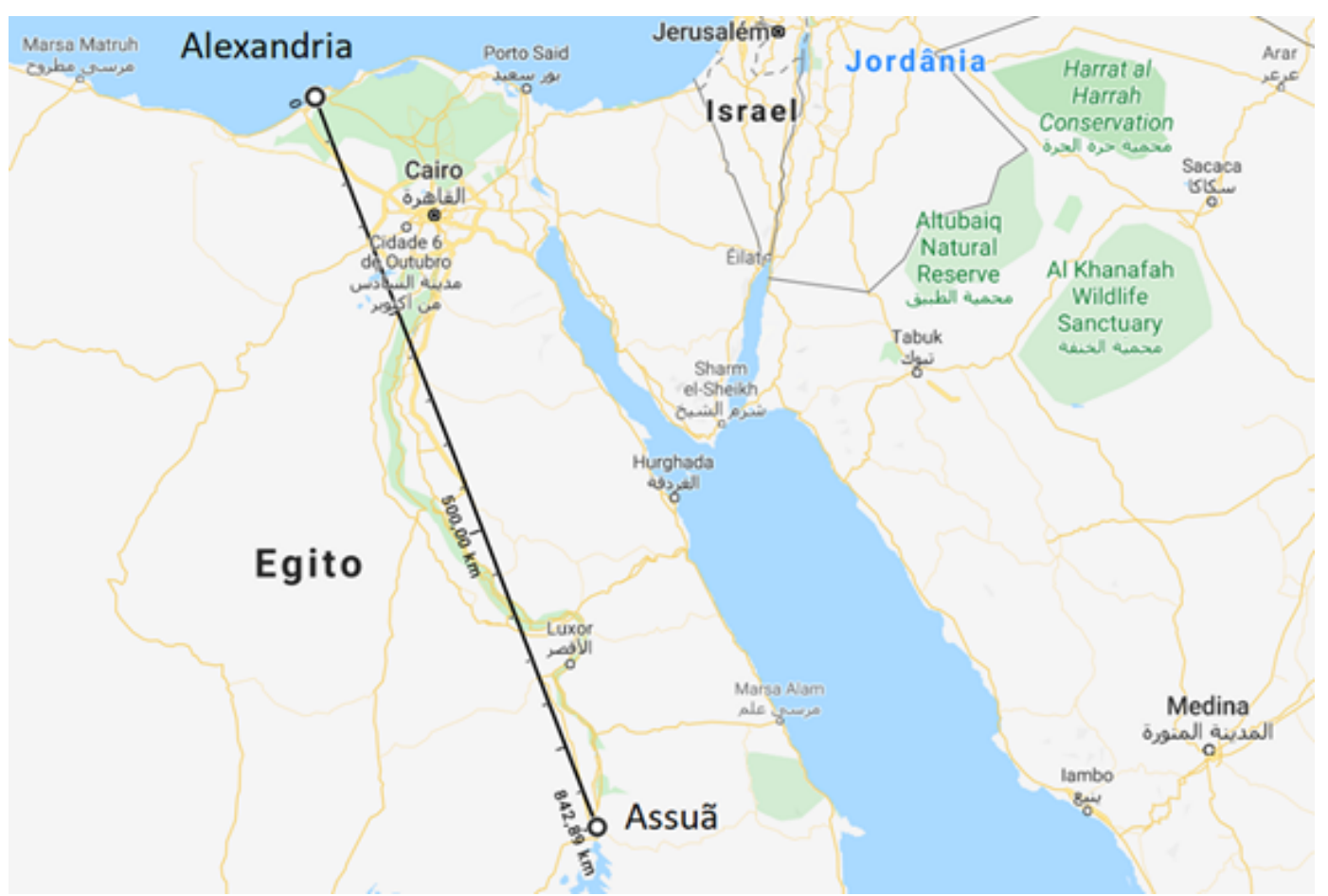

Fonte: Imagem elaborada pelos autores sobre mapa produzido pelo “Google Maps".

Todavia, só é possível concluir que a circunferência da Terra é 50 vezes a distância entre Siena/Assuã e Alexandria, a partir do conhecimento de que a abertura angular do arco geodésico entre as duas cidades (a partir do centro do globo terrestre) for de pouco mais que $7^{\circ}$. Mas como 
Eratóstenes conseguiu descobrir esse ângulo? Eratóstenes sabia de um fato importante: que no dia do solstício de verão do hemisfério norte, uma haste colocada na posição vertical na cidade de Siena, ao meio-dia, quase não tinha sombra, ou seja, o Sol se situava exatamente a pino (no zênite), com os raios solares formando um ângulo reto com a superfície da Terra naquela cidade (COSTA, 2000); ele soube disso por um manuscrito da biblioteca de Alexandria - o ambiente de trabalho de Eratóstenes - que continha a informação de que o Sol iluminava o fundo de um poço (vertical) de Siena/Assuã, ao meio-dia, no solstício de verão (VERDET, 1991).

O solstício de verão é definido como o momento do ano no qual a duração da noite é mínima e a duração do dia (com iluminação do sol) é máxima: no hemisfério norte o solstício de verão ocorre entre 20 e 21 de junho, enquanto no hemisfério sul (onde está a maior parte do Brasil), o solstício de verão ocorre entre 20 e 21 de dezembro. Além disso, as linhas dos dois Trópicos - de Câncer no hemisfério norte e de Capricórnio no hemisfério sul - são definidas como constituídas pelos pontos da superfície terrestre nos quais ao meio-dia verdadeiro do dia de solstício de verão uma haste vertical não tem sombra (o comprimento da sombra é nulo). Portanto, Siena está situada bem próxima ao trópico de Câncer, assim como, por sinal, a cidade de São Paulo está situada bem próxima do Trópico de Capricórnio.

A engenhosidade de Eratóstenes foi perceber que, para achar o tamanho da circunferência da Terra, era necessário medir o tamanho da sombra de uma haste vertical situada na cidade de Alexandria (onde ele vivia) ao meio-dia no momento do solstício de verão no hemisfério norte (20 ou 21 de junho). A propósito, o "meio-dia verdadeiro" (BOCZOKO, 1984) é definido exatamente pelo momento em que essa sombra tinha o menor valor possível, ou seja, mesmo que ele não tivesse um relógio preciso (como temos hoje), era só ele ir acompanhando as medidas do tamanho da sombra que iria gradualmente diminuir ao longo da manhã até atingir um valor mínimo ao meio-dia e começar a aumentar gradativamente ao longo da tarde: esse valor mínimo era o tamanho da sombra ao meio-dia! A razão entre o tamanho da sombra e a altura da haste é igual a tangente do ângulo que os raios de sol que chegavam em Alexandria (neste momento) formavam com a vertical, ou seja, com a própria haste: portanto a partir dos valores que ele aferiu para esses dois comprimentos, foi possível deduzir que esse ângulo era de cerca de $7,2^{\circ}$. Finalmente, por meio de considerações geométricas, foi possível demonstrar que esse é também o ângulo do arco de linha geodésica entre as cidades de Siena/Assuã e Alexandria, tomado a partir do centro do globo terrestre. A igualdade destes dois ângulos (com 7,2 $)$ pode ser observada na Figura 4, ao destacarmos, em primeiro lugar, o feixe de retas paralelas constituídas pelos raios da luz solar e, em segundo lugar, a reta diagonal a essas retas paralelas que forma os dois ângulos assinalados na figura que, pelo fato de serem alternos internos, têm que ser iguais (Figura 5).

Para chegar à sua conclusão quantitativa acerca do tamanho da circunferência da Terra, Eratóstenes teve que articular vários conhecimentos: que o Sol estava muito distante da Terra de modo que os raios solares chegavam paralelos a Terra; que ao meio-dia do solstício de verão do hemisfério norte, em Siena/Assuã uma haste vertical tem sombra de comprimento nulo; a distância aproximada entre Siena/Assuã e Alexandria; o comprimento da haste vertical 


\section{Figura 4 - Representação da solução geométrica obtida por Eratóstenes}

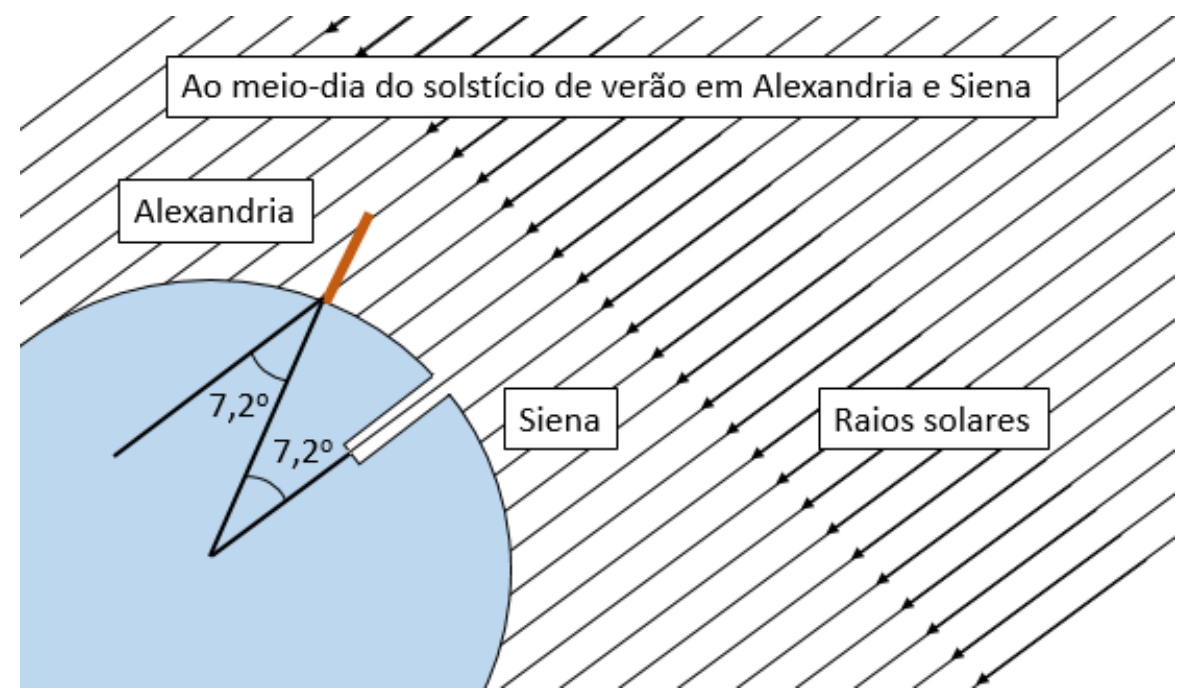

Fonte: Elaborada pelos autores.

em Alexandria e da sua sombra ao meio-dia do solstício de verão do hemisfério norte; alguns conhecimento básicos de geometria, como por exemplo o fato de que quando uma reta corta de forma diagonal duas retas paralelas, os denominados ângulos alternos internos são iguais.

Figura 5 - Igualdade de ângulos alternos internos â e ê. A reta t é diagonal às retas $\mathbf{r}$ e $\mathrm{s}$, que são paralelas entre si

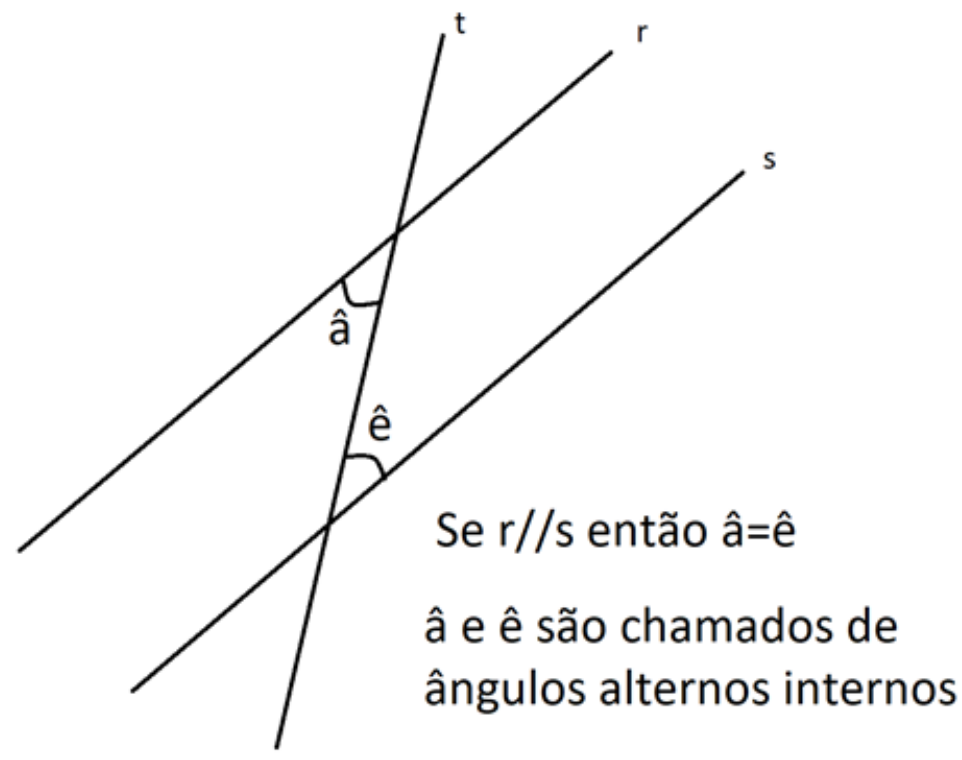

Fonte: Elaborada pelos autores.

É importante ressaltar que Eratóstenes não “viu” com seus olhos que a Terra era esférica. Sua medida não foi uma observação direta, mas sim o resultado de um processo que necessita tanto de medidas de comprimentos, quanto de pressupostos teóricos, dados experimentais associados a conhecimentos existentes e raciocínio lógico dedutivo. É possível tentar explicar as diferenças nas medidas das sombras de hastes verticais ao meio-dia do solstício de verão em Alexandria e em Siena/Assuã de outra forma, sem concluir que a Terra tenha formato aproxi- 
madamente esférico? Até hoje não há qualquer outro modo que explique isso satisfatoriamente e sem inconsistências lógicas. A conclusão de Eratóstenes, portanto, é que a Terra é esférica e que (nas unidades atuais) a circunferência da Terra é da ordem de $40.000 \mathrm{~km}$, sendo que seu diâmetro é aproximadamente esse valor dividido por 3,14 (ou seja, de cerca de $12.740 \mathrm{~km}$ ) e seu raio é aproximadamente esse valor dividido por 6,28 (ou seja, de cerca de $6.370 \mathrm{~km}$ ).

Em resumo: Eratóstenes conseguiu determinar o tamanho, ou seja, o comprimento da circunferência da Terra, observando basicamente as sombras produzidas pelos raios solares incidentes sobre duas varetas posicionadas verticalmente em duas diferentes localidades do nosso planeta em um determinado dia e horário do ano (o meio-dia verdadeiro do dia de solstício de verão no hemisfério norte) e aplicando um raciocínio geométrico sobre os valores obtidos para as sombras (FERREIRA; BISCH, 2019).

\section{O EXPERIMENTO DE ERATÓSTENES NO CONTEXTO DO BRASIL DE HOJE}

As diretrizes da Base Nacional Comum Curricular - BNCC (BRASIL, 2018) apontam para as possibilidades de aulas práticas que estimulem a criatividade dos estudantes e promovam ativamente a construção de experimentos. Resultados de pesquisas na área de ensino de Ciências apontam que a utilização de atividades experimentais é uma estratégia bastante eficiente para despertar tanto o interesse, quanto a dedicação dos alunos; neste sentido, no caso específico do ensino de astronomia, é de fundamental importância levar em conta o caráter observacional e prático desta ciência (LANGHI, 2017).

Nesse sentido, no âmbito de aulas implementadas por um dos autores deste trabalho (I. P. S.) para turmas de $6^{\circ}$ e $9^{\circ}$ anos do Ensino Fundamental de uma escola situada na cidade de São Paulo, foi cogitada a possibilidade de mostrar aos estudantes um experimento científico para evidenciar o formato esférico do planeta em que vivemos. Para tanto, usou-se como ponto de partida o vídeo "Você sabe qual é o formato real da Terra?", elaborado pelo "Programa Ciência em Show" e disponibilizado pela Secretaria da Educação do Estado de São Paulo no YouTube, que faz uma releitura do famoso experimento de Eratóstenes para os dias atuais, no Brasil, usando para isso as cidades de São Paulo (SP) e São Luís (MA). As aulas aplicadas com esse vídeo foram realizadas durante o mês de maio de 2020, portanto dentro do período de quarentena devido à pandemia de COVID-19. De forma geral os estudantes gostaram do vídeo, mas houve críticas sobre a imagem "forjada" de um cientista medindo uma sombra em São Luís, uma etapa importante do experimento, e também sobre a duração do vídeo (cerca de 11 minutos), considerada muito longa por vários estudantes. Assim, surgiu a ideia de criar um vídeo análogo e com uma filmagem real, in loco, da medição das sombras em duas cidades; esse vídeo, de duração menor (cerca de 8 minutos) e intitulado "Qual o formato da Terra?"7 está disponível para ser acessado por qualquer pessoa na internet.

Após uma pesquisa feita por meio da rede social Instagram, foi encontrado um parceiro

${ }^{6}$ Disponível em: <https://www.youtube.com/watch?v=XeOkvt2pb78\&t=25s > . Acesso em: 26 set. 2020.

${ }^{7}$ Disponível em: <https://www.youtube.com/watch?v=wDWH6Bnbbbc >. Acesso em: 26 set. 2020. 
(outro autor deste artigo, J. D. V. C. F.), professor na cidade de Pedreiras no Maranhão, que se animou com a ideia e topou a realização da experiência em conjunto. O experimento combinado entre ambos os professores foi montado com um cabo de vassoura de tamanho padrão, com 1 metro de altura, na vertical, apoiado em uma garrafa PET com uma porção d'água para estabilizar o sistema em cada uma das duas cidades. Embora de montagem simples, o objetivo foi satisfatoriamente alcançado: ter uma estrutura com tamanho padronizado em dois pontos distantes do planeta, para medição simultânea da sombra projetada com a luz solar.

É importante destacar que as cidades de Pedreiras e São Paulo distam aproximadamente $2.126 \mathrm{~km}$ entre si (em linha reta) e estão dispostas praticamente no mesmo meridiano, tendo valores de longitude muito próximos. Em números aproximados, a cidade de São Paulo tem latitude de $-23,53^{\circ}$ e longitude de $-46,46^{\circ}$, enquanto a cidade de Pedreiras tem latitude de $-4,62^{\circ}$ e longitude de $-44,67^{\circ}$; latitudes negativas significam que as cidades estão ao sul da linha do Equador, enquanto longitudes negativas significam que as cidades estão a oeste do meridiano de Greenwich que passa por Londres. O sistema de mapeamento do Google Maps foi o recurso usado para a obtenção dos dados de latitude e longitude dos locais de São Paulo e Pedreiras, onde as medidas ocorreram (Figura 6). Em módulo, a diferença entre as longitudes das cidades de São Paulo e Pedreiras é, portanto, de aproximadamente $1,79^{\circ}$, enquanto a diferença entre as latitudes é de aproximadamente $18,91^{\circ}$. A premissa de que as duas cidades têm aproximadamente a mesma longitude é importante para validar o experimento síncrono realizado em ambas as localidades. Comparativamente, a distância entre São Paulo e Pedreiras ( $2.126 \mathrm{~km}$ ) é bem maior que a distância entre Alexandria e Siena/Assuã ( $843 \mathrm{~km}$ ). Além disso as duas primeiras cidades estão mais alinhadas quanto à longitude do que as duas últimas: em módulo, a diferença entre longitudes no primeiro caso é de $1,79^{\circ}$ e no segundo caso é de $2,94^{\circ}$.

\section{Figura 6 - Distância em linha reta entre as cidades de Pedreiras e São Paulo}

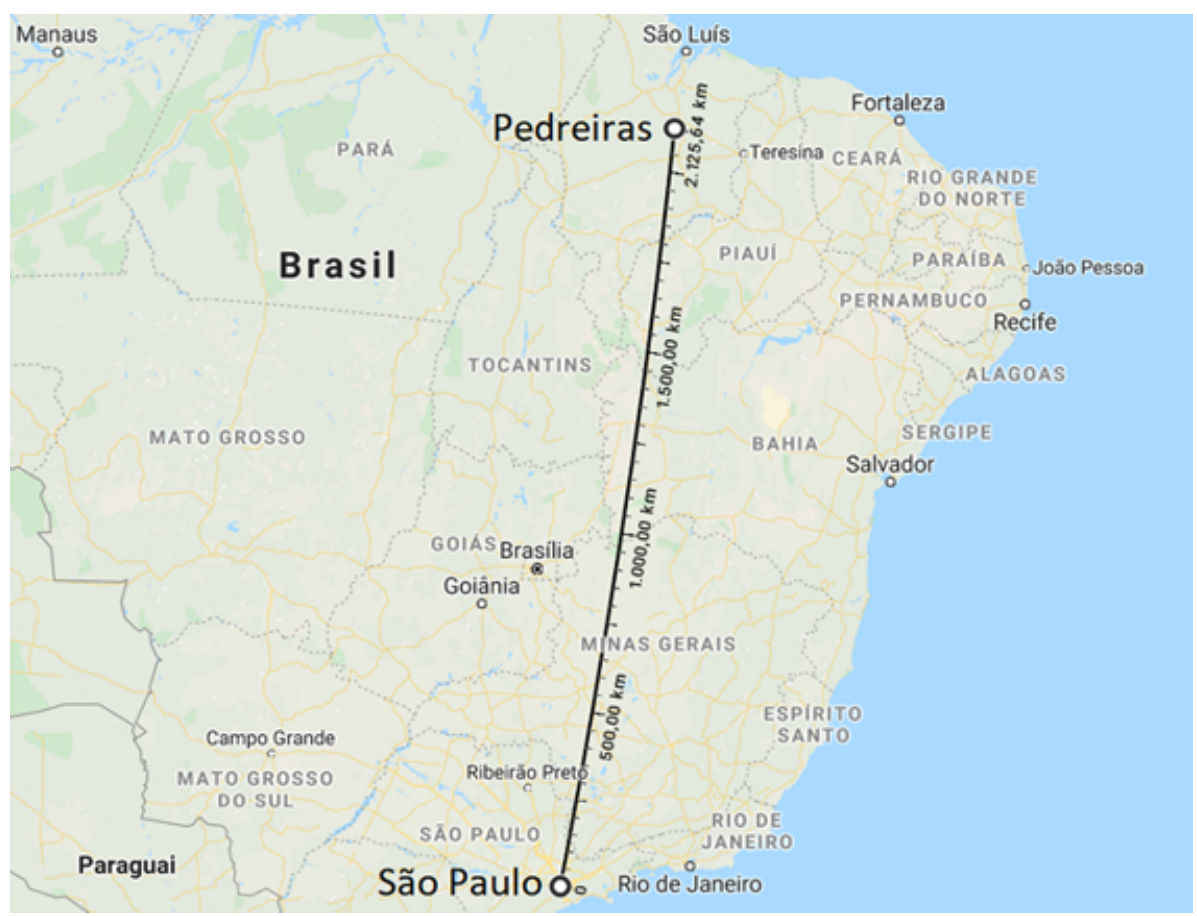

Fonte: Imagem elaborada pelos autores sobre mapa produzido pelo “Google Maps”. 
Desse modo, no dia 27 de maio de 2020, os dois professores (e autores desse trabalho) que moram nas cidades de São Paulo e Pedreiras, passaram a manhã em contato via aplicativo de celular WhatsApp, aguardando o melhor momento para fazer as medições, pois o céu estava parcialmente nublado em Pedreiras. Entre 10:36 e 10:53, as nuvens deram uma chance e foram realizadas as medidas. Cada qual gravou um vídeo mostrando a sombra da haste vertical de 1 metro $(100 \mathrm{~cm})$ em sua cidade (de modo simultâneo): em Pedreiras mediu-se uma sombra de $57 \mathrm{~cm}$ e em São Paulo mediu-se uma sombra de $120 \mathrm{~cm}$.

Considerando que os raios solares que incidem sobre a Terra chegam paralelamente entre eles (devido ao fato de o Sol estar extremamente distante da Terra), era de se esperar sombras com tamanhos iguais se a Terra fosse plana. A diferença no tamanho das sombras, contudo, foi muito acentuada. Mesmo considerando as incertezas do processo de medição a sombra na cidade de São Paulo mostrou-se com mais que o dobro do tamanho da sombra em Pedreiras. O resultado do experimento mostra, portanto, que o modelo da Terra plana não se sustenta e é inconsistente com as evidências experimentais.

Mais de dois milênios depois de Eratóstenes, a facilidade em realizar tais medidas aumentou consideravelmente. A comunicação instantânea (largamente utilizada em tempos da pandemia de coronavírus) propiciada pela internet e pelas redes sociais, permitiu aos dois professores, localizados nas cidades de São Paulo e Pedreiras, comparar o tamanho das sombras praticamente ao mesmo tempo. No passado a história conta que, enquanto diretor da biblioteca de Alexandria, Eratóstenes tinha conhecimento de que no solstício de verão, ao meio-dia, o Sol ficava exatamente no zênite. Para comprovar que o mesmo não acontecia em Alexandria, foi necessário para Eratóstenes (que vivia nessa cidade) apenas esperar o solstício de verão do próximo ano e torcer por um dia sem nuvens para realizar a medida do tamanho da sombra de uma haste vertical ao meio-dia, já que ele tinha, previamente, uma estimativa razoável para a distância (em linha reta) aproximada entre Alexandria e Siena, duas cidades que estavam conectadas pelo Rio Nilo.

A intenção de realizar este experimento nos dias de hoje era mostrar a inconsistência da teoria terraplanista com a diferença visível entre os tamanhos das sombras. Portanto, a princípio, a experiência tinha um caráter qualitativo, sem maiores preocupações com os valores das medidas. Entretanto os dados colhidos permitiram uma abordagem também quantitativa do experimento realizado, de modo a propiciar uma estimativa interessante da circunferência da Terra.

Em São Paulo, para a estaca com $100 \mathrm{~cm}$ disposta perpendicularmente ao solo, a medida da sombra foi de $120 \mathrm{~cm}$. Nesse caso, temos um triângulo retângulo como o da Figura 7. 
Figura 7 - Haste vertical de $100 \mathrm{~cm}$ e sombra de $120 \mathrm{~cm}$, em São Paulo

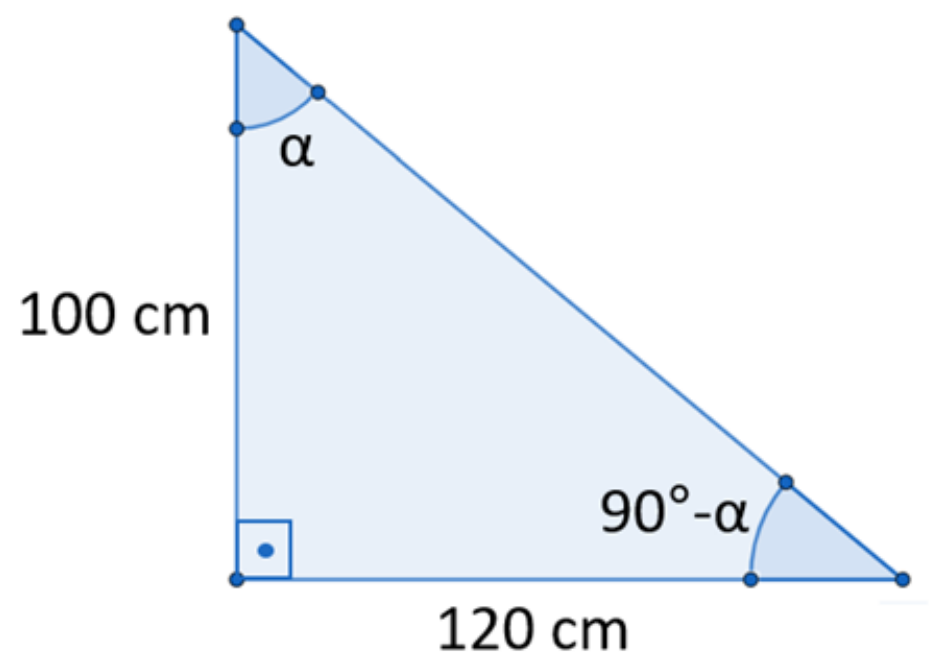

Fonte: Elaborada pelos autores.

Aplicando a relação trigonométrica da tangente para o ângulo $\alpha$ tem-se que:

$$
\begin{gathered}
\operatorname{tg} a=\text { cateto oposoto / cateto adjacente } \\
\operatorname{tg} a=120 / 100 \\
\operatorname{tg} a=1,2 \\
a=\operatorname{arctg}(1,2) \\
a \cong 0,88 \text { rad ou } a \cong 5^{\circ}
\end{gathered}
$$

Em Pedreiras, para a estaca com $100 \mathrm{~cm}$ disposta perpendicularmente ao solo, foi medida uma sombra de $57 \mathrm{~cm}$. Deste modo, temos o triângulo retângulo da Figura 8.

Figura 8 - Haste vertical de $100 \mathrm{~cm}$ e sombra de $57 \mathrm{~cm}$ em Pedreiras

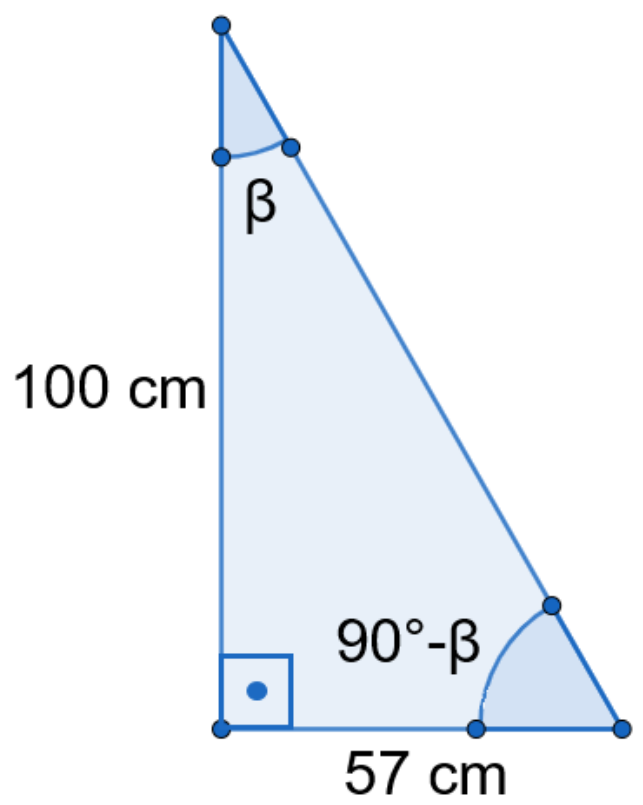

Fonte: Elaborada pelos autores. 
Aplicando a relação trigonométrica da tangente para o ângulo $\beta$ tem-se que:

$$
\begin{gathered}
\operatorname{tg} \beta=\text { cateto oposto / cateto adjacente } \\
\operatorname{tg} \beta=57 / 100 \\
\operatorname{tg} \beta=0,57 \\
\beta=\operatorname{arctg}(0,57) \\
\beta \cong 0,52 \operatorname{rad} \text { ou } \beta \cong 30^{\circ}
\end{gathered}
$$

O paralelismo entre os raios solares que incidem sobre a Terra permite afirmar que a abertura angular $\theta$, a partir do centro da Terra, referente ao arco de linha geodésica entre as cidades de São Paulo e Pedreiras é igual à diferença entre os ângulos acima mencionados, $\alpha$ e $\beta$. A imagem da Figura 9 demonstra geometricamente essa conclusão, a partir de duas propriedades: 1- quando uma reta corta (em diagonal) duas outras retas que são paralelas entre si, os ângulos alternos internos são iguais um ao outro; 2- quando duas retas se cruzam, os ângulos opostos pelo vértice são iguais entre si. É importante notar que os ângulos $\alpha$ e $\beta$ (nas figuras 7 e 8) são tomados em relação à vertical e não em relação à horizontal. No experimento original de Eratóstenes uma das estacas não produzia sombra (a que estava em Siena), ao meiodia do solstício de verão. Portanto, como o ângulo $\beta$ era nulo, não era necessário realizar qualquer subtração de ângulos: o ângulo de abertura angular $\theta$ a partir do centro da Terra entre Alexandria e Siena era igual ao próprio ângulo $\alpha$ formado, em Alexandria, pelos raios solares com a vertical, ao meio-dia do solstício de verão.

\section{Figura 9 - Representação esquemática do experimento realizado em Pedreiras e São Paulo}

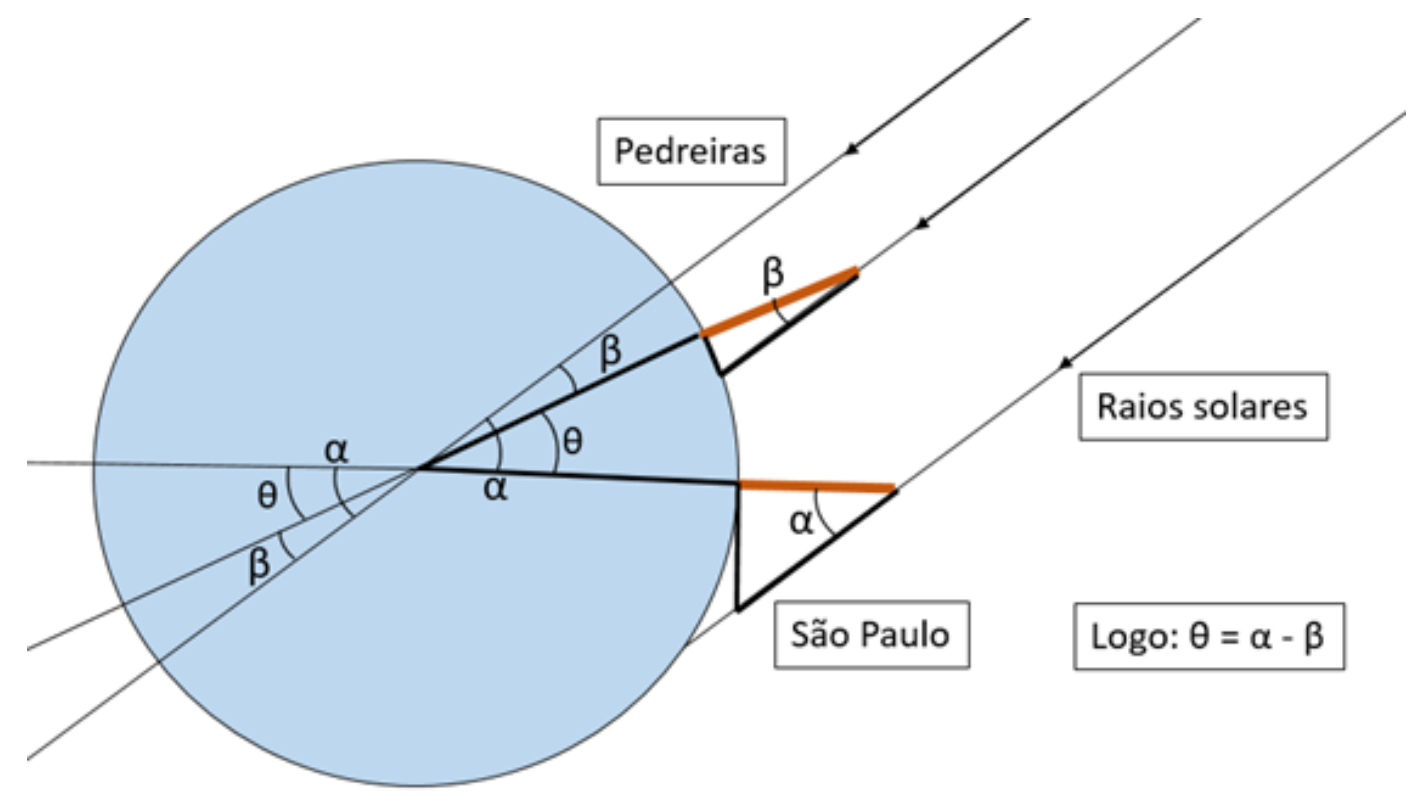

Fonte: Elaborada pelos autores.

No caso do experimento descrito neste artigo, o ângulo de abertura $\theta$ a partir do centro da Terra entre as cidades de Pedreiras e São Paulo é: 


$$
\begin{gathered}
\theta=\alpha-\beta \\
\theta \cong 50^{\circ}-30^{\circ} \\
\theta \cong 20^{\circ}
\end{gathered}
$$

O valor obtido acima ficou próximo do valor da diferença entre as latitudes das respectivas cidades que é $23,53^{\circ}-4,62^{\circ}=18,91^{\circ} \cong 19^{\circ}$ : a diferença entre os dois valores é de cerca de $1^{\circ}$. Considerando que para essa abertura angular $\theta$ há uma distância correspondente de cerca de 2.126 km (o afastamento entre as cidades de Pedreiras e São Paulo, em "linha reta" sobre o globo terrestre), pode-se estimar o tamanho da circunferência terrestre $\mathrm{C}$ por uma simples regra de três:

$$
\begin{gathered}
20^{\circ} \rightarrow 2.126 \mathrm{~km} \\
360^{\circ} \rightarrow C \mathrm{~km} \\
\therefore C \cong 38.268 \mathrm{~km}
\end{gathered}
$$

Sabemos atualmente que o comprimento efetivo da circunferência da Terra vale 40.000 $\mathrm{km}$, portanto a estimativa do experimento realizado para esse comprimento apresentou um erro de 4,3\% em relação ao tamanho real. Um possível fator para esse erro é que, durante a realização do experimento, enquanto em São Paulo o centro da garrafa que segurava o experimento foi tomado como zero para medida do comprimento da sombra, em Pedreiras, a medida do comprimento da sombra foi tomada a partir da borda da garrafa; além disso, a difusividade da sombra da haste tornou difícil estabelecer com precisão a posição da extremidade da sombra. Outro fator para o erro pode estar no fato de que as longitudes de Pedreiras e São Paulo não são exatamente as mesmas: a diferença entre elas é de $1,79^{\circ}$.

\section{CONSIDERAÇÕES FINAIS}

Os "PCN+ Ensino Médio" para Ciências da Natureza, Matemática e suas Tecnologias (BRASIL, 2002), que apresentam Orientações Educacionais Complementares aos Parâmetros Curriculares Nacionais, sugerem que o tema "Universo, Terra e vida" venha a ser trabalhado junto com a observação de fenômenos que no dia a dia revelam os movimentos da Terra, ao invés de privilegiar sínteses. Adicionalmente, a unidade temática "Terra e sistema solar", faz a sugestão de apresentar as relações existentes entre os movimentos da Terra, da Lua e do Sol para descrever fenômenos observados como a duração do dia e da noite, as estações do ano, as fases da lua e eclipses: nesse sentido, compreender a posição relativa do Sol ao longo do dia ou do ano é fundamental. Por sua vez, as "Orientações Curriculares para o Ensino Médio - Ciências da Natureza, Matemática e suas Tecnologias" afirmam que pode ser bastante interessante levar para a sala da aula a discussão de ideias geométricas que resolveram certos problemas na Antiguidade, dentre eles o problema clássico do cálculo do raio da Terra, resolvido por Eratóstenes no século III a.C. (BRASIL, 2006). Finalmente, de acordo com a BNCC (BRASIL, 2018), é 
importante que os alunos elaborem e testem hipóteses, bem como que exerçam a imaginação e a criatividade.

Um trabalho educacional realizado a partir de locais situados em diferentes pontos da superfície da Terra, permite que os alunos compreendam melhor conceitos abstratos, como coordenadas, latitude, longitude e fusos horários, bem como reflitam sobre os fatores que afetam a precisão dos resultados obtidos. Adicionalmente, este tipo de atividade coloca em destaque a importância da colaboração para a produção de conhecimentos científicos e para a resolução de problemas (PEREIRA, 2006), algo importante no processo de educação científica.

Este presente artigo procurou apresentar uma atividade experimental que pode ser feita atualmente sem muitas dificuldades e que é análoga à conhecida medida da circunferência da Terra realizada por Eratóstenes há mais de 2200 anos. O uso das redes sociais e de meios de comunicação modernos ajudou bastante nessa tarefa. A atividade realizada está imbuída da premissa de que, na ciência, uma proposição, para ser considerada científica, tem que ser testada das mais variadas formas, nos mais diversos locais e sob as mais diferentes condições, por experimentos tentando falsear à exaustão a hipótese enunciada inicialmente.

Finalmente, a realização do experimento evidenciou que a construção da ciência também se dá pela superação de um empirismo ingênuo e estrito, do tipo "estou vendo que a Terra nas redondezas em que vivo é plana, logo a Terra deve ser plana" ou "estou vendo ao longo de todos os dias o sol se movimentar pelo céu de leste para oeste e não vejo a Terra se movimentar debaixo de meus pés, logo é o Sol que deve estar se movimentando e orbitando em torno da Terra".

No decorrer do experimento analisado neste artigo para evidenciar a esfericidade da Terra e estimar o tamanho da sua circunferência foram feitas certas medidas, feitas certas pressuposições (o paralelismo entre os raios do Sol que chegam à Terra), empregados certos conhecimentos (a distância entre duas cidades, por exemplo), analisadas possíveis alternativas de explicação, verificadas as inconsistências lógicas dessas alternativas e desenvolvidos raciocínios dedutivos geométricos. A produção de conhecimento, portanto, não ocorre sobre uma tábula rasa, em um papel em branco sobre o qual as "observações puras" vão revelar a verdade sem qualquer referencial teórico! A produção de novos conhecimentos se estrutura sobre conhecimentos anteriores e, portanto, ocorre em um contexto de pressupostos teóricos associado a um certo grau de complexidade que vai muito além da ideia de senso comum associada ao ditado popular "ver para crer". 


\section{REFERÊNCIAS}

ALVIM, M. Quem são e o que pensam os brasileiros que acreditam que a terra é plana. BBC Brasil, 16 set. 2017. Disponível em: <https://www.bbc.com/portuguese/brasil-41261724>. Acesso em: 15 mai. 2020.

BEZERRA, E. V. L. Investigando a terra plana com o Stellarium. 2019. 56 f. Monografia de Conclusão de Curso (Especialização em Inovação e Tecnologias na Educação) - Universidade Tecnológica Federal do Paraná, Curitiba. Disponível em: <http://repositorio.roca.utfpr.edu.br/ jspui/bitstream/1/15333/1/CT_INTEDUC_I_2019_23.pdf>. Acesso em: 20 mai. 2020.

BOCZOKO, R. Conceitos de Astronomia. São Paulo: Edgard Blucher, 1984.

BRASIL. PCN+ Ensino Médio: Orientações educacionais complementares aos parâmetros curriculares nacionais (ciências da natureza, matemática e suas tecnologias). Brasília: Ministério da Educação (MEC) / Secretaria de Educação Média e Tecnológica (SEMTEC), 2002. Disponível em: <http://portal.mec.gov.br/seb/arquivos/pdf/CienciasNatureza.pdf > . Acesso em: 10 jun. 2020.

BRASIL. Orientações Curriculares para o Ensino Médio: Ciências da natureza, matemática e suas tecnologias (Vol. 2). Brasília: Ministério da Educação (MEC) / Secretaria de Educação Básica (SEB), 2006. Disponível em: <http://portal.mec.gov.br/seb/arquivos/pdf/book_volum e_02_internet.pdf $>$. Acesso em: 11 jun. 2020.

BRASIL. Base Nacional Comum Curricular (BNCC). Brasília: Ministério da Educação (MEC), 2018. Disponível em: <http://basenacionalcomum.mec.gov.br/images/BNCC_E I_EF_110518_versaofinal_site.pdf $>$ Acesso em: 3 jun. 2020.

COSTA, J. R. V. Eratóstenes e a circunferência da terra. Astronomia no Zênite, 2000. Disponível em: <https://www.zenite.nu/eratostenes-e-a-circunferencia-da-terra $>$. Acesso em: 17 ago. 2021.

CREASE, R. P. Os Dez Mais Belos Experimentos Científicos. Rio de J aneiro: Jorge Zahar Editor, 2006.

D’ANCONA, M. Pós-verdade: a nova guerra contra os fatos em tempos de fake news. Barueri, SP: Faro Editorial, 2018.

FERREIRA, C. A.; BISCH, S. M. Qual é o tamanho do universo? Uma proposta de sequência de ensino investigativo sobre os métodos de eratóstenes e aristarco para medir os tamanhos da terra e da lua. RELEA, n. 28, p. 27-46, 2019. Disponível em: <https://www.relea.ufscar.br/in dex.php/relea/article/view/398 >. Acesso em: 17 ago. 2021.

GARCIA, R. 7\% dos brasileiros afirmam que terra é p lana, m ostra pesquisa. Folha de São Paulo, 14 jul. 2019. Disponível em: <https://www1.folha.uol.com.br/ciencia/2019/07/7-dosb rasileiros-afirmam-que-terra-eplana-mostra-pesquisa.shtml>. Acesso e m: 25 mai. 2020.

LANDRUM, A. Youtube as a primary propagator of flat earth philosophy. In: ANNUAL MEETING OF AMERICAN ASSOCIATION FOR THE ADVANCEMENT OF SCIENCE. Proceedings [...]. Washington, DC, USA, 2019.

LANGHI, R. Projeto eratóstenes brasil: autonomia docente em atividades experimentais de astronomia. Caderno Brasileiro de Ensino de Física, v. 34, n. 1, p. 6-46, 2017. Disponível em: <https://periodicos.ufsc.br/index.php/fisica/article/view/2175-7941.2017v34n1p6>. Acesso em: 17 ago. 2021. 
OLSHANSKY, A. et al. Conspiracy theorizing and religious motivated reasoning: Why the earth 'must' be flat. Lubbock (USA). 2018. Tese (Doutorado em artes) - Texas Tech University, USA, 2018. Disponível em: <https://ttu-ir.tdl.org/bitstream/handle/2346/82666/OLSHANS KY-THESIS-2018.pdf? sequence=1\&isAllowed=y > . Acesso em: 28 mai. 2020.

PEREIRA, P. C. R. Revivendo eratóstenes. RELEA, n. 3, p. 19-38, 2006. Disponível em: $<$ https://www.relea.ufscar.br/index.php/relea/article/view/74>. Acesso em: 17 ago. 2021.

PIVARO, G. F. A crença numa terra plana e os ambientes virtuais: identificando r elações e construções de conhecimento. In: ENCONTRO NACIONAL DE PESQUISA EM EDUCAÇÃO EM CIÊNCIAS, 12., 2019, Natal. Anais[...]. Natal: ABRAPEC, 2019. Disponível em: <http://abrapecnet.org.br/enpec/xii-enpec/anais/resumos/1/R2128-1.pdf>. Acesso em: 29 mai. 2020.

ROSA, C. T. W. da; DARROZ, L. M.; TYBURSKI, L. A forma da terra no ensino fundamental: a qual fonte de informação os alunos outorgam maior autoridade epistêmica? Revista Thema, v. 15, n. 3, p. 1019-1033, 2018. Disponível em: <http://periodicosnovo.ifsul.edu.br/index.php/ thema/article/view/980/873 >. Acesso em: 17 ago, 2021.

SANTOS, A. J. d. J.; VOELZKE, M. R.; ARAÚJO, M. S. T. d. O projeto eratóstenes a reprodução de um experimento histórico como recurso para a inserção de conceitos da astronomia no ensino médio. Caderno Brasileiro de Ensino de Física, v. 29, n. 3, p. 1137-1174, dez. 2012. Disponível em: <https://periodicos.ufsc.br/index.php/fisica/article/view/2175-7941.2012v29 n3p1137>. Acesso em: 29 abr. 2020.

VERDET, J. Uma história da astronomia. Rio de Janeiro: Jorge Zahar Editor, 1991. 